\title{
Characterising Dark Net Marketplace Purchasers in a Sample of Regular Psychostimulant
}

Users

Joe Van Buskirk ${ }^{1}$, Amanda Roxburgh ${ }^{1}$, Raimondo Bruno ${ }^{2}$, Sundresan Naicker ${ }^{1}$, Simon Lenton ${ }^{3}$, Rachel Sutherland ${ }^{1}$, Elizabeth Whittaker ${ }^{1}$, Natasha Sindicich ${ }^{1}$, Allison Matthews ${ }^{2}$, Kerryn Butler ${ }^{1}$, Lucinda Burns ${ }^{1}$

1. National Drug and Alcohol Research Centre (NDARC), University of New South Wales, Sydney, New South Wales, 2052, AUSTRALIA

2. University of Tasmania, School of Medicine, Hobart, Tasmania, 7000, AUSTRALIA

3. National Drug Research Institute, Curtin University, Perth, Western Australia, 6000, AUSTRALIA

\section{Corresponding author:}

Mr Joe Van Buskirk

Research Officer

National Drug and Alcohol Research Centre

University of New South Wales

22-32 King St

Randwick, 2031, Australia

Telephone: + 61293850333

Fax: + 61293850222

Email: j.vanbuskirk@unsw.edu.au

Abstract: 284 words

Text: 3,757 words 


\section{Introduction}

The rise of the internet as an integral part of daily life has led to an increase in its use for the discussion, distribution, and purchase of illicit substances (Walsh, 2011). Online purchasing of illicit substances initially appeared driven by a rise in the interest and availability of new psychoactive substances (NPS); substances that often produce similar neurological effects to traditional illicit drugs but are not yet controlled by international legislation (Walsh, 2011). However, with the advent of the 'dark net' (also known as the 'hidden web' or 'deep' web) retail of more traditional illicit substances has risen steadily (Van Buskirk, Roxburgh, Bruno, \& Burns, 2014a). Dark net marketplaces exist on the TOR network, which works by rerouting a user's connection through multiple anonymous servers, thereby masking the original internet protocol (IP) address of the user (Christin, 2013). Unlike the 'surface web', the dark net consists of websites not accessible via search engines, and the exact address must be known in order to gain access. The anonymity this provides, along with the use of decentralised cryptocurrencies such as BitCoin (BitCoin, 2015) for payment, theoretically allows for the retail and purchasing of illicit substances with less fear of prosecution by law enforcement (Barratt, 2012). The most notable marketplace to date has been the Silk Road, which rose to popularity in 2011 and served to greatly expand the availability of substances online. Following the seizure of the Silk Road by law enforcement in November 2013, several other dark net marketplaces have emerged in its wake (including Silk Road 2.0, which was also subsequently shut down by law enforcement in November 2014 (Rushe, 2014), with varying popularity and longevity (Van Buskirk, Roxburgh, Bruno, \& Burns, 2014b; Van Buskirk, Roxburgh, Farrell, \& Burns, 2014).

There has been increasing interest among researchers in monitoring activity on these dark net marketplaces (Buxton \& Bingham, 2015; Orsolini, Francesconi, Papanti, Giorgetti, \& Schifano, 2015). The Drugs and New Technologies (DNeT) project run at the National Drug and Alcohol Research Centre (NDARC) in Sydney, Australia, has been recording activity on various marketplaces for the past five years in a standardised manner, allowing for the analysis of trends. Specifically, DNeT has monitored the availability of substances, the number of active retailers and the reaction of marketplaces to law enforcement operations and internal scams (Dolliver, 2015; Van Buskirk, Roxburgh, Bruno, \& Burns, 2015; Van Buskirk, Roxburgh, Farrell, et al., 2014). This research provides important information on trends in substance availability from dark net marketplaces, the number of retailers, and how marketplaces adjust following disruption. It does not, however, provide information on the characteristics of consumers purchasing from these marketplaces. A recent paper published by Barratt, Ferris, and Winstock (2014) analysed data from a large, international sample of 9,470 recent drug users who completed an on-line survey promoted through the media in 2012 (before the closure of the Silk Road) and found approximately 6\% of their sample had 
purchased drugs from the Silk Road, with rates of purchasing highest among participants from the USA (10\%) and lowest among Australian participants (4\%). However, this low percentage of Australians is apparently at odds with the American Federal Bureau of Investigation (FBI) documents released in the wake of the Silk Road closure, in which it was determined that Australian customers were overrepresented on the original Silk Road relative to Australia's population (Ormsby, 2015). The most commonly purchased illicit substance across USA, UK and Australian participants was MDMA, followed by cannabis and LSD. Among those participants consuming drugs purchased on the Silk Road (without necessarily having made the purchase themselves), the main motivations for using the website were the greater range, and higher quality of drugs available, as well as the convenience of online purchasing (Barratt et al., 2014). However, this analysis did not compare those purchasing from the Silk Road with those purchasing from other sources, and so it is difficult to typify this population, and whether they differ from those purchasing solely from street markets.

The Ecstasy and related Drugs Reporting System (EDRS) has been monitoring patterns of substance use and associated characteristics of regular psychostimulant users (RPU) in Australia since 2003. In this sample, participants are eligible if over the preceding six months they have used on at least six different occasions one of the following psychostimulant substances: 3,4-methylenedioxymethamphetamine (MDMA), 3,4-methylenedioxy-amphetamine (MDA), methamphetamine, cocaine and any non-prescribed use of pharmaceutical stimulants (e.g. methylphenidate, dextroamphetamine). Over the past two years, the EDRS has reported an increasing proportion of participants sourcing NPS and traditional illicit substances online. In 2012, 3.6\% of those sampled reported sourcing any drug online in their last transaction, with $5.7 \%$ of the sample having purchased online in their last transaction in 2013 Sindicich and Burns (2013, 2014). However, data were not collected in these years on the specific online source from which substances were purchased, and so the extent to which online purchasers used dark net marketplaces as opposed to 'surface web' retailers remains unknown. In addition, no data were collected on the specific motivations of this sample for purchasing online over traditional street markets.

The aims of the paper are therefore two-fold. First, to quantify differences between individuals who purchase from dark net marketplaces compared to those who do not according to self-reported demographic criteria, patterns of past and present drug use, and their health and legal status as reported in the EDRS. Second, to describe the motivation of users for accessing dark net marketplaces as reported in the EDRS, therefore extending the findings of Barratt et al. (2014).

\section{Method}




\section{$\underline{\text { Participants }}$}

The sample incorporated 745 participants recruited as part of the 2014 EDRS. This study is designed to monitor self-reported changes in illicit drug market use and preference across Australia (for full methodology see Sindicich and Burns (2015). Participants were recruited for face-to-face interviews during March-July 2014 using a purposive sampling process, via advertisements in universities and street press, and peer referral. Participant eligibility included an age of 16 or older, use of a psychostimulant drug at least once monthly in the preceding six months, and residence in the city of recruitment for at least the 12 months prior to interview. The study received approval from the University of New South Wales Human Research Ethics Committee.

\section{$\underline{\text { Measures }}$}

The full EDRS structured interview comprised demographic questions including gender, age, education level, employment and sexuality. Participants were asked about their usage and purchasing of a variety of licit and illicit substances, as well as mental and sexual health questions. Questions were asked pertaining to the participants' past month criminal activity, including arrest in the last year and recent property, dealing, fraud and violent crime. For clarification, property crime examples were given which included shoplifting, break and enter, stealing a car and receiving stolen goods. Dealing was defined as having sold drugs to someone for cash profit above an amount to cover personal use.

To measure dark net use specifically, respondents were asked whether they had ever used a dark net marketplace to purchase drugs, and whether they had done so in the preceding 12 months. Those found to have recently purchased from dark net marketplaces were asked if they purchased from domestic (i.e. Australian) retailers on these marketplaces, or if they purchased from retailers in other countries. Buying from domestic retailers offers a relatively lower level of risk of detection compared to importing drugs across the Australian border, due to stringent screening of packages at the international border (Australian Crime Commission, 2014). Participants were asked what substances they had purchased, and whether their purchases were made for themselves or others. Participants were then asked about their main motivation for purchasing online, any negatives associated with purchasing online (both including free text response options), their likelihood of purchasing online in the future, and if their last ordered package arrived without detection.

\section{Data Analysis}

Analysis was conducted using IBM SPSS Statistics release 22.0 (IBM Corporation, 2013). Binary logistic regression (using the Wald statistic) was used to model the likelihood of dark net use across 
variables such as gender, age, extent and frequency of drug use and criminal activity. As dark net purchasers are hypothesised to be more 'entrenched' drug users, variables associated with the extent of drug use, such as crime and mental health, were included for potential confounding. Dealing, property crime, fraud and violent crime were included to determine the types of crime participants were involved in. All variables with a significance level less than 0.25 at the univariate level were entered into the binary logistic regression model to control for potential confounding.

Results

Of the 745 EDRS participants, 82 reported that they had ever purchased from the dark net (12\% of the sample), with 66 (80\% of all dark net users; $10 \%$ of the sample, $95 \% \mathrm{Cl}: 7 \%-11 \%$ ) reporting having done so in the previous year. Motivations and characteristics of purchasing from dark net marketplaces among recent purchasers are presented in 
Table 1. The majority of recent dark net purchasers reported they had purchased from the original Silk Road, with the majority reporting they had bought from international retailers, either exclusively (38\%), or from both Australian and international retailers (30\%). Most reported purchasing for both themselves and others (83\%), and stated that 'a few' of their friends also purchased from the dark net $(73 \%)$. Notably, seven participants ( $11 \%$ of purchasers) stated none of their friends purchased online. MDMA was nominated as the most commonly purchased drug, followed by LSD, cannabis and new psychoactive substances (NPS). Participants largely cited the cheaper price online as their main motivation for purchasing online over street markets $(38 \%)$, and the higher quality of substances online (30\%). The mostly commonly cited negatives of purchasing online were that packages did not arrive (27\%), the slow overall process of purchasing online $(22 \%)$ and the difficulty of the process (20\%). Free-response text variables, asking about the motivation for, and negatives associated with, purchasing online, were analysed for recurring themes, with all resulting options cited by fewer than five participants each. In the interest of retaining anonymity, these are not reported. The vast majority of dark net purchasers stated their last ordered package arrived without being intercepted (88\%).

[Insert TABLE 1 about here]

The 16 participants who reported purchasing from the dark net but had not done so in the preceding year were excluded from subsequent analyses. Recent purchasers from the dark net $(n=66)$ were compared to the larger sample who had never reported purchasing from the dark net $(n=679$; Table 2). Due to low numbers reporting past month fraud or violent crime ( $2 \%$ and $4 \%$ of the sample, respectively), these two categories were collapsed as a single variable. At the univariate level, those who reported recent dark net purchasing were more likely to be male $(O R 3.24, p<0.001)$ and aged under 25 (OR 2.70, $p=0.007$ ). No other demographic differences were found between the groups. In terms of substance use, dark net purchasers were more likely to report using: any NPS in the preceding six months (OR 7.51, $p<0.001$ ); psychedelic drug classes (OR 13.26, $p<0.001$ ); cannabis daily (OR 2.01, $p=0.031$ ); ecstasy weekly or more (OR 2.20, $p=0.005$ ); and two or more ecstasy pills in each session of use (OR 1.91, $p=0.016)$ in the preceding six months. They were also more likely to report having committed a property crime (OR 3.05, $p<0.001)$ and a dealing crime (OR 2.58, $p=0.001$ ) in the month preceding interview. No between-groups differences were found for the sexual health or mental health items assessed.

[Insert TABLE 2 about here] 
All variables reaching a minimum significance level of 0.25 were entered into a base model, which was then adjusted using backwards elimination to determine a final model, controlling for confounding at each step. This resulted in six significant independent predictors of dark net purchasing in the last six months: being male (AOR 2.79, $p=0.012$ ); being aged under 25 (AOR 2.60, $p=0.031$ ); reported use of any NPS in the preceding six months (AOR 2.71, $p=0.005$ ); reported use of a psychedelic drug class in the preceding six months (AOR 7.31, $p=0.002$ ); daily cannabis use (AOR 2.07, $p=0.044$ ); and reported property crime in the preceding month (AOR 3.11, $p=0.001$ ). There were no indications of problems with multicollinearity (no variance inflation factor for any variable exceeded 1.5).

\section{Discussion}

This is the first paper to document the specific nature of internet drug purchasing amongst a group of Australians who use psychostimulants regularly. Though a small proportion of the sample reported ever (11\%) and recently (10\%) purchasing substances on the dark net, proportions are higher than those from the 2015 Global Drug Survey sample (4.5\% of the sample reported ever purchasing from the dark net and 1.9\% purchasing in the preceding 12 months; Winstock, 2015). Purchasing occurred for a variety of reasons; in particular the cheaper price of drugs and better quality of substances available, which corroborates findings by Barratt et al. (2014). Substances in Australia are traditionally more expensive than other countries, likely due to Australia's relative isolation (Sindicich \& Burns, 2013, 2014), and as such dark net marketplaces appear to represent a cheaper alternative to street markets (Van Buskirk, Roxburgh, Bruno, \& Burns, 2013). This is supported by the finding that almost $70 \%$ of the dark net purchasers in the current study ordered from retailers outside of Australia, despite a higher legal risk of detection associated with international importation compared with domestic mail, due to stringent screening process of mail at the international border (Australian Crime Commission, 2014).

MDMA was the most commonly purchased substance on the dark net. This finding is not surprising given participants were recruited based on their psychostimulant use (with $98 \%$ having recently used ecstasy), and is consistent with findings from dark net monitoring which have found MDMA in the top three most commonly available substances across marketplaces (Van Buskirk, Roxburgh, et al., 2014a, 2014b; Van Buskirk et al., 2015). Similarly, Barratt et al. (2014) found MDMA was the most commonly sourced substance from the original Silk Road among those with awareness of the market, while Soska and Christin (2015) found that MDMA was the second most commonly purchased substance across all dark net markets. A survey of Silk Road buyers by Van Hout and Bingham (2013) also found MDMA was a favourite drug among international buyers. Australians are 
relatively high users of MDMA, with current estimates putting the rate of recent 'ecstasy' usage among Australian adults at 2.9\% (Australian Institute of Health and Welfare, 2014), compared with $1.7 \%$ in England and Wales (Home Office, 2015) and 0.9\% in the USA (National Institute on Drug Abuse, 2015). This is despite variable purity of MDMA in Australia in the past five years (Australian Crime Commission, 2014; Scott \& Burns, 2011; Sindicich \& Burns, 2012). Qualitative research suggests MDMA is of higher and more consistent quality on dark net marketplaces compared with street markets, and thus dark net markets may represent an attractive and reliable source of MDMA for Australians (Van Hout \& Bingham, 2013). Much of the data on purity on dark net markets, however, comes from subjective reports rather than chemical verification. It would be of benefit for future research to independently verify the purity of substances sold on dark net marketplaces to assess such reports.

Dark net purchasers were more likely to have recently used a psychedelic drug, which corroborates research published by Bruno et al. (2012) who use the 2011 EDRS sample. In that study, psychedelic NPS users were found to have higher rates of criminal and drug involvement compared with other NPS users; they were more likely to be younger, male and commenced using ecstasy at a younger age. Though that study looked specifically at psychedelic NPS, rather than psychedelic drug use overall, it is likely that, in Australia at least, dark net purchasers and RPU using psychedelics are related populations. This finding supports conclusions made previously regarding distinct populations of psychostimulant users, with distinct preferences for substances $(\mathrm{Wu}$, Ringwalt, Weiss, \& Blazer, 2009). The RPU accessing dark net marketplaces in the current study may represent the more innovative, 'psychonaut' drug users, a term used to describe people who are more likely to actively seek out new substances for the purposes of achieving altered states of consciousness (European Monitoring Centre for Drugs and Drug Addiction (EMCDDA), 2004). Psychedelics such as LSD are typically cheaper and less variable in quality than substances such as MDMA and cocaine in Australia (Sindicich \& Burns, 2013). As the two main motivating factors for purchasing from the dark net were better quality and cheaper price, there may therefore be less motivation to source psychedelics from dark net marketplaces over traditional markets. It is not possible to tell from this paper whether those purchasing from dark net markets were doing so exclusively, or if they were also sourcing substances in traditional markets. Considering that around half of the dark net purchasers had only made one or two purchases, it is likely they are not using these marketplaces exclusively to source substances. Dark net marketplaces appear to complement, rather than replace, traditional markets. Future research should investigate the extent to which dark net markets may be replacing, rather than supplementing, traditional avenues of drug purchasing. 
Previous research suggests that the feedback and reputation system of dark net marketplaces incentivises retailers to supply less adulterated substances and online communities attached to these marketplaces can disseminate harm reduction messages among users (Buxton \& Bingham, 2015; Van Hout \& Bingham, 2014). This is especially salient in light of the finding that dark net usage was associated with increased likelihood of NPS use. There is limited research on the short and long term effects of these substances and outcomes of chronic use. In addition, many of these substance categories such as the NBOMe and $2 \mathrm{C}-\mathrm{x}$ families vary greatly in their individual dosages, with little to no difference in appearance, which in turn contributes to an elevated overdose risk(Lawn, Barratt, Williams, Horne, \& Winstock, 2014). Similarly, new substances continue to emerge (EMCDDA, 2014), making it difficult to stay abreast of content and variability of these substances and associated harms. Credible harm reduction messages delivered through peer networks could be effective in counteracting adverse outcomes. Future research should investigate the validity of harm reduction messages currently delivered in dark net communities to assess the viability of such an approach.

There were 16 participants identified who had purchased from dark net markets in the past, but not in the previous year. It is unclear why these participants ceased using dark net markets for purchasing substances. It is possible they discontinued their use in favour of traditional avenues of purchase due to the cited negatives of dark net purchasing. In this way, the initial motivations for using the dark net for purchasing, such as lower prices and higher quality, may have been overshadowed by the relative difficulty of the process, the slowness of the process or the risk of packages not arriving. Alternatively, they may have discontinued their use due to packages being intercepted by law enforcement and faced with criminal charges. Lastly, the overall instability of the dark net in the wake of marketplace closures and scams (Van Buskirk et al., 2015; Van Buskirk, Roxburgh, Farrell, et al., 2014) may have caused users to disengage with these markets. The small sample size precluded any analysis of this group for differences from recent dark net purchasers and non-dark net purchasers. As such, it is not possible to determine why RPU may cease using dark net markets, and this represents another avenue for future research.

Due to the sensitive nature of the self-report data collected from participants, there is potential for social desirability bias among participants, resulting in an under-reporting of criminal activity. In addition, as many measures referred to recent use, recall bias may cast some doubt on the validity of quoted timeframes. However, previous research has indicated good reliability and validity of selfreport data in similar contexts (Darke, 1998), and these concerns are unlikely to pose a significant problem for the findings reported here. The small sample size of dark net purchasers precluded indepth thematic analysis of the free response variables for motivations and negatives of dark net 
purchasing. However, the vast majority of participants (76-80\%) answered within the offered responses. Due to the cross-sectional design of the study, and that data are limited to Australian participants from urban centres, conclusions on generalisability to the general population are limited and there may be a non-responder bias. However, a 2004 assessment of the EDRS data in one Australian state concluded that it had high generalisability to population estimates (Topp, Barker, \& Degenhardt, 2004). In any case, these data represent a snapshot of regular psychostimulant users' motivations for, and correlates of, using dark net marketplaces and can be used to identify areas of concern for further research.

\section{Conclusions}

The advent of online drug marketplaces and the exponential growth in the types of substances available seems to have revolutionised the way some people purchase illicit substances. For those Australians purchasing drugs on the dark net, country borders do not seem to be a significant barrier to purchase, as illustrated by the large proportion purchasing from international retailers, with a wider range of substances available than ever before. The current study represents the first analysis of RPU to explore differences between those purchasing from the dark net and those who do not. Future areas of research include replicating analyses in other countries to corroborate the present findings of distinct substance use patterns of dark net users, as well as purchasing preferences and motivations for accessing dark net markets over traditional street markets. 
References

Australian Crime Commission. (2014). 2013-2014 Illicit Drug Data Report. In Australian Crime Commission (Ed.), Illicit Drug Data Report. Canberra, Australia.

Australian Institute of Health and Welfare. (2014). National Drug Strategy Household Survey detailed report 2013 Drug statistics series no. 28. Cat. no. PHE 183. Canberra: AlHW.

Barratt, M. J. (2012). Silk Road: Ebay for drugs. Addiction, 107(3), 683-683. doi: 10.1111/j.13600443.2011.03709.x

Barratt, M. J., Ferris, J. A., \& Winstock, A. R. (2014). Use of Silk Road, the online drug marketplace, in the United Kingdom, Australia and the United States. Addiction, 109(5), 774-783. doi: 10.1111/add.12470

BitCoin. (2015). BitCoin P2P digital currency. Retrieved 6th June, 2015, from http://bitcoin.org/

Bruno, R., Matthews, A. J., Dunn, M., Alati, R., Mcllwraith, F., Hickey, S., ... Sindicich, N. (2012). Emerging psychoactive substance use among regular ecstasy users in Australia. Drug Alcohol Depend, 124(1-2), 19-25. doi: http://dx.doi.org/10.1016/i.drugalcdep.2011.11.020

Buxton, J., \& Bingham, T. (2015). The Rise and Challenge of Dark Net Drug Markets: Policy Brief 7. Swansea, Wales: Global Drug Policy Oberservatory.

Christin, N. (2013). Traveling the Silk Road: A measurement analysis of a large anonymous online marketplace. Paper presented at the World Wide Web Conference, Rio de Janeiro, Brazil. Working Paper retrieved from http://arxiv.org/abs/1207.7139

Darke, S. (1998). Self-report among injecting drug users: A review. Drug \& Alcohol Dependence, 51(3), 253-263. doi: 10.1016/50376-8716(98)00028-3

Dolliver, D. S. (2015). Evaluating drug trafficking on the Tor Network: Silk Road 2, the sequel. International Journal of Drug Policy, 26(11), 1113-1123. doi: 10.1016/j.drugpo.2015.01.008

EMCDDA. (2004). Report on the Risk Assessment of 2C-I, 2C-T-2 and 2C-T-7 in the Framework of the Joint Action on New Synthetic Drugs. Belgium: European Monitoring Centre for Drugs and Drug Addiction.

EMCDDA. (2014). The state of the drugs problem in Europe - Annual Report. European Monitoring Centre for Drugs and Drug Addiction, Luxembourg.

Home Office. (2015). Drug Misuse: Findings from the 2014/15 Crime Survey for England and Wales Statistical Bulletin 03/15. London: Home Office.

IBM Corporation. (2013). IBM SPSS Statistics for Windows, Version 22.0. Armonk, NY: IBM Corporation.

Lawn, W., Barratt, M., Williams, M., Horne, A., \& Winstock, A. (2014). The NBOMe hallucinogenic drug series: Patterns of use, characteristics of users and self-reported effects in a large international sample. Journal of Psychopharmacology, 28(8), 780-788. doi: 10.1177/0269881114523866

National Institute on Drug Abuse. (2015). DrugFacts: Nationwide Trends from the National Survey on Drug Use and Health (NSDUH). Retrieved 29th of July, 2015, from http://www.drugabuse.gov/publications/drugfacts/nationwide-trends

Ormsby, E. (2015). What is it with Aussies and the darknet markets? Retrieved 29th of July, 2015, from http://allthingsvice.com/2015/05/21/what-is-it-with-aussies-and-the-darknet-markets/

Orsolini, L., Francesconi, G., Papanti, D., Giorgetti, A., \& Schifano, F. (2015). Profiling online recreational/prescription drugs' customers and overview of drug vending virtual marketplaces. Human Psychopharmacology: Clinical and Experimental, 30(4), 302-318. doi: 10.1002/hup. 2466

Rushe, D. (2014). Silk Road 2.0's alleged owner arrested as drugs website shuttered by FBI. Retrieved 7th of July, 2015, from http://www.theguardian.com/technology/2014/nov/06/silk-road-20-owner-arrested-drugswebsite-fbi 
Scott, L. A., \& Burns, L. (2011). Has ecstasy peaked? A look at the Australian ecstasy market over the past eight years. EDRS Drug Trends Bulletin, April 2011. Sydney: National Drug and Alcohol Research Centre, University of New South Wales.

Sindicich, N., \& Burns, L. (2012). An overview of the 2012 EDRS: Ecstasy returns and the Emerging class of drugs EDRS Drug Trends Bulletin, October 2012. Sydney: National Drug and Alcohol Research Centre, University of New South Wales.

Sindicich, N., \& Burns, L. (2013). Australian Trends in Ecstasy and related Drug Markets 2012. Findings from the Ecstasy and Related Drugs Reporting System (EDRS). Australian Drug Trend Series No. 100. Sydney: National Drug and Alcohol Research Centre, University of New South Wales.

Sindicich, N., \& Burns, L. (2014). Australian Trends in Ecstasy and related Drug Markets 2013. Findings from the Ecstasy and Related Drugs Reporting System (EDRS). Australian Drug Trend Series No. 118. Sydney: National Drug and Alcohol Research Centre, University of New South Wales.

Sindicich, N., \& Burns, L. (2015). Australian Trends in Ecstasy and related Drug Markets 2014. Findings from the Ecstasy and Related Drugs Reporting System (EDRS). Australian Drug Trend Series No. 136. Sydney: National Drug and Alcohol Research Centre, University of New South Wales.

Soska, K., \& Christin, N. (2015). Measuring the longitudinal evolution of the online anonymous marketplace ecosystem. Paper presented at the 24th USENIX Security Symposium, Washington, D.C.

Topp, L., Barker, B., \& Degenhardt, L. (2004). The external validity of results derived from ecstasy users recruited using purposive sampling strategies. Drug Alcohol Depend, 73(1), 33-40. doi: 10.1016/j.drugalcdep.2003.09.001

Van Buskirk, J., Roxburgh, A., Bruno, R., \& Burns, L. (2013). Drugs and the Internet, Issue 1. Sydney, Australia: National Drug and Alcohol Research Centre.

Van Buskirk, J., Roxburgh, A., Bruno, R., \& Burns, L. (2014a). Drugs and the Internet, Issue 2. Sydney, Australia: National Drug and Alcohol Research Centre.

Van Buskirk, J., Roxburgh, A., Bruno, R., \& Burns, L. (2014b). Drugs and the Internet, Issue 3. Sydney, Australia: National Drug and Alcohol Research Centre.

Van Buskirk, J., Roxburgh, A., Bruno, R., \& Burns, L. (2015). Drugs and the Internet, Issue 4. Sydney, Australia: National Drug and Alcohol Research Centre.

Van Buskirk, J., Roxburgh, A., Farrell, M., \& Burns, L. (2014). The closure of the Silk Road: what has this meant for online drug trading? Addiction, 109(4), 517-518. doi: 10.1111/add.12422

Van Hout, M. C., \& Bingham, T. (2013). 'Surfing the Silk Road': A study of users' experiences. International Journal of Drug Policy, 21, 359-363.

Van Hout, M. C., \& Bingham, T. (2014). Responsible vendors, intelligent consumers: Silk Road, the online revolution in drug trading. International Journal of Drug Policy, 25(2), 183-189. doi: http://dx.doi.org/10.1016/i.drugpo.2013.10.009

Walsh, C. (2011). Drugs, the Internet and change. Journal of Psychoactive Drugs, 43(1), 55-63. doi: 10.1080/02791072.2011.566501

Winstock, A. R. (2015). The Global Drug Survey 2015 findings. Retrieved 19th of October, 2015, from http://www.globaldrugsurvey.com/the-global-drug-survey-2015-findings/

Wu, L.-T., Ringwalt, C. L., Weiss, R. D., \& Blazer, D. G. (2009). Hallucinogen-related disorders in a national sample of adolescents: the influence of ecstasy/MDMA use. Drug Alcohol Depend, 104(1-2), 156-166. doi: 10.1016/j.drugalcdep.2009.04.014 
Table 1: Characteristics and motivations of recent dark net purchasers.

\begin{tabular}{|c|c|c|}
\hline & $\mathrm{n}=66$ & $\%$ \\
\hline \multicolumn{3}{|l|}{ Source of Drug } \\
\hline Silk Road 1.0 & 62 & 94 \\
\hline Other dark net marketplace & 18 & 27 \\
\hline \multicolumn{3}{|c|}{ Purchased from Australian or international retailers } \\
\hline Australian & 19 & 29 \\
\hline International & 25 & 38 \\
\hline Both & 20 & 30 \\
\hline \multicolumn{3}{|c|}{ Frequency of purchasing in the last 12 months } \\
\hline Once & 17 & 26 \\
\hline Twice & 13 & 20 \\
\hline 3-5 times & 17 & 26 \\
\hline More than 5 times & 18 & 27 \\
\hline \multicolumn{3}{|c|}{ Who drugs were purchased for } \\
\hline Participant & 7 & 11 \\
\hline Participant and others & 52 & 83 \\
\hline \multicolumn{3}{|l|}{ Drug Purchased $\#$} \\
\hline MDMA & 43 & 65 \\
\hline LSD & 21 & 32 \\
\hline Cannabis & 17 & 26 \\
\hline Methamphetamine & 12 & 19 \\
\hline Cocaine & 11 & 17 \\
\hline Any NPS ${ }^{\wedge}$ & 16 & 24 \\
\hline - $\quad$ NBOMe & 5 & 8 \\
\hline $2 C-x$ & 7 & 11 \\
\hline - $\quad$ Other NPS ${ }^{\wedge}$ & 12 & 18 \\
\hline Any other drug & 18 & 27 \\
\hline \multicolumn{3}{|c|}{ Main motivation for purchasing online ${ }^{\#}$} \\
\hline Cheaper prices & 25 & 38 \\
\hline Better quality of substances & 20 & 30 \\
\hline Greater availability online & 5 & 8 \\
\hline Other & 15 & 23 \\
\hline \multicolumn{3}{|c|}{ Negatives of accessing dark net marketplaces } \\
\hline Packages did not arrive & 20 & 30 \\
\hline Slow process & 16 & 24 \\
\hline More legal risk & 15 & 23 \\
\hline Difficult process & 13 & 20 \\
\hline No negatives & 9 & 14 \\
\hline \multicolumn{3}{|c|}{ Proportion of friends purchasing online } \\
\hline About half & 8 & 11 \\
\hline A few & 48 & 73 \\
\hline None & 7 & 11 \\
\hline \multicolumn{3}{|l|}{ Last package arrived } \\
\hline Yes & 58 & 88 \\
\hline No & 5 & 8 \\
\hline
\end{tabular}

NB: Participants were given the option to refuse to answer. As percentages reflect proportion of the whole sample of dark net purchasers, these do not always sum to $100 \%$. "To preserve anonymity, options with fewer than five participants individually endorsing them were collapsed. "New psychoactive substances. Other NPS included: N,N-Dimethyltryptamine (DMT), 4methylmethcathinone (mephedrone), methylone, Methylenedioxypyrovalerone (MDPV), 3-MeO-2Oxo-PCE (methoxetamine), and salvia divinorum 
Table 2: Characteristics of RPU who had recently purchased substances from the dark net compared with those who had not

\begin{tabular}{|c|c|c|c|c|c|c|}
\hline & \multicolumn{2}{|c|}{ Non-Dark Net Users $(n=679)$} & \multicolumn{2}{|c|}{ Dark Net Users $(n=66)$} & \multirow[b]{2}{*}{ OR $(95 \% \mathrm{Cl})$} & \multirow[b]{2}{*}{ AOR $(95 \% \mathrm{Cl})$} \\
\hline & $n$ & $\%$ & $\mathrm{n}$ & $\%$ & & \\
\hline \multicolumn{7}{|l|}{ Demographics } \\
\hline Male & 430 & 63 & 56 & 85 & $3.24(1.63-6.47)^{* * *}$ & $2.79(1.25-6.20)^{*}$ \\
\hline Age under 25 & 495 & 73 & 58 & 88 & $2.70(1.26-5.75)^{* *}$ & $2.60(1.09-6.19)^{*}$ \\
\hline First tried ecstasy under 18 & 339 & 50 & 40 & 61 & $1.54(0.92-2.56)^{\%}$ & $0.89(0.50-1.61)$ \\
\hline GLBT & 74 & 11 & 8 & 12 & $1.13(0.52-2.45)$ & - \\
\hline Unemployed & 100 & 15 & 10 & 15 & $1.03(0.51-2.09)$ & - \\
\hline Completed courses after secondary school & 315 & 47 & 27 & 42 & $0.81(0.48-1.35)$ & - \\
\hline \multicolumn{7}{|l|}{ Drug Use (last six months) } \\
\hline Used any NPS ${ }^{\#}$ & 239 & 35 & 53 & 80 & $7.51(4.01-14.05)^{* * *}$ & $2.71(1.34-5.48)^{* *}$ \\
\hline Used any psychedelic drug class ${ }^{\&}$ & 366 & 54 & 62 & 94 & $13.26(4.77-36.85)^{* * *}$ & $7.31(2.12-25.17)^{* *}$ \\
\hline Daily cannabis use & 100 & 15 & 17 & 26 & $2.01(1.11-3.63)^{*}$ & $2.07(1.02-4.19)^{*}$ \\
\hline Weekly or more ecstasy use & 174 & 26 & 28 & 44 & $2.20(1.31-3.72)^{* *}$ & $1.70(0.93-3.11)$ \\
\hline More than two ecstasy tablets taken in typical session & 185 & 28 & 28 & 42 & $1.91(1.14-3.21)^{* *}$ & $1.36(0.76-2.43)$ \\
\hline Used stimulants for $48 \mathrm{hrs}$ or more without sleep & 245 & 36 & 27 & 41 & $1.23(0.3-2.05)$ & - \\
\hline Used other drugs to come down from ecstasy & 363 & 54 & 43 & 67 & $1.77(1.03-3.04)^{*}$ & $0.90(0.49-1.68)$ \\
\hline Overdose on a stimulant drug (last 12 months) & 120 & 18 & 15 & 24 & $1.44(0.78-2.65)$ & - \\
\hline \multicolumn{7}{|l|}{ Sexual Health } \\
\hline Protection last sexual encounter while on drugs & 179 & 26 & 17 & 26 & $0.97(0.54-1.73)$ & - \\
\hline Ever diagnosed with an STI & 111 & 17 & 5 & 8 & $0.44(0.17-1.12)^{\%}$ & $0.54(0.20-1.47)$ \\
\hline \multicolumn{7}{|l|}{ Mental Health } \\
\hline Any mental health problem (last six months) & 189 & 28 & 16 & 25 & $0.85(0.47-1.52)$ & - \\
\hline K10 Score (mean) & & 17.9 & & 16.4 & & - \\
\hline \multicolumn{7}{|l|}{ Crime (last month) } \\
\hline Recent property crime & 86 & 13 & 20 & 31 & $3.05(1.72-5.41)^{* * *}$ & $3.11(1.59-6.08)^{* *}$ \\
\hline Recent for-profit dealing & 160 & 24 & 29 & 45 & $2.58(1.54-4.35)^{* * *}$ & $1.14(0.62-2.09)$ \\
\hline Recent fraud or violent crime & 39 & 6 & 6 & 9 & $1.66(0.68-4.09)$ & - \\
\hline Arrested in the last 12 months & 85 & 13 & 7 & 11 & $0.84(0.37-1.90)$ & - \\
\hline
\end{tabular}

NB: ${ }^{*} p<0.25 ;{ }^{*} p<0.05 ;{ }^{* *} p<0.01 ;{ }^{* * *} p<0.001 ;$ GLBT, Gay, lesbian, bisexual or transgender orientation; ${ }^{\#}$ New psychoactive substance; ${ }^{\circledR}$ Psychedelic drugs asked about included LSD, Magic Mushrooms, MDA; STI, sexually transmitted infection; K10, Kessler Psychological Distress Scale; OR, odds ratio; AOR, adjusted odds ratio; $\mathrm{Cl}$, confidence interval. 